\title{
Treacher-Collins syndrome
}

\author{
Ambarkova Vesna \\ Faculty of Dental Medicine, Department of Paediatric and Preventive Dentistry, ,University St. Cyril and Methodius, Skopje, Republic of Macedonia
}

Treacher-Collins syndrome is genetic disease that alters the development of bones and other tissues in the face. Signs and symptoms of thissyndrome, vary fromalmost unnoticeable face changes to severe facial and ear deformities, cleft palate and restricted airway. The syndrome is named after Edward Treacher Collins, an English surgeon and ophthalmologist who described its essential traits in 1900.

Treacher-Collins syndrome can be passed down through families or most of the time do not affect another member of the family. Mutations in TCOF1 and POLR1D cause the autosomal dominant form of Treacher Collins, and mutations in POLR1C cause the autosomal recessive form [1]. The integration of molecular biology, cell biology, mouse genetics and experimental embryology has recently provided novel insightsinto the molecular pathogenesis of TCS.

When an affected child is born, it is important to investigate the parents to determine whether the affected gene is present, because the parent could have a mild form of the disease that has not been diagnosed. The diagnosis of Treacher Collins syndrome relies upon clinical and radiographic findings. Prenatal diagnosis cannot be guaranteed. Mutations in the main genes responsible for TCS can be detected with chorionic villus sampling or amniocentesis. Rare mutations may not be detected by these methods. Ultrasonography can be used to detect craniofacial abnormalities later in pregnancy, but may not detect milder cases. The TCOF1gene is located on the long arm (q) of chromosome 5 , a region which is designated $5 \mathrm{q} 32$. TCOF1encodes a protein known as treacle [1]. De Peratta et al find a positive correlation between the expression of CNBP and TCOF1 in mesenchymal cells from both control and TCS subject. Based on that, they suggest CNBP as a additional target for new alternative therapeutic treatments to reduce craniofaciald efects not only in TCS but also in other neurocistopathies [2].

Deficient ribosome biogenesis which occur in this syndrome is insufficient to meet the proliferation and growth needs of cells during development of the embryo. It is assumed that the changes occurfrom 19-28 day ofearly intrauterine development due to destruction of the trigeminal neuron cells (of unknown origin) and is associated with generalized lack of mesenchymal tissue, leading to underdevelopment of the upper jaw and lower jaw. Because TCS is highly variable, researchers speculate that additional genetic and possibly environmental factors may also play a role in the variable severity of the disorder (guide for TCS.

One possibility for improving the surgical outcomemight be the incorporation of stem cells in therapeutictreatment of craniofacial abnormalities. There is enormouspotential in the application of stem cells in engineeringtissues, such as bone and cartilage, that constitute the headand facial tissues so severely disrupted in TCS. However, atpresent, there is no universal recommendation for theinuterocorrection of prenatally diagnosed craniofacial anomalies and the decision to pursue fetal surgicalintervention carries with it the potential for dual mortality (mother and fetus). Thus, fetal surgery at present remains experimental and controversial [3].

All described changes in Treacher-Collins syndrome can be divided in three groups: otological, ophthalmic and dental findings. Otological findings are Conductive hearing loss (ranging from mild to severe) usually due to malformations of structures within the middle ear, absent, abnormally small or underdeveloped external ears, malformed external ears (hypoplasia of ear shells, low position of the ear shells (earlobes), presence of skin extensions and blind fistula in the area before the ear shells), the absence of the outer ear canal(atresia), stenosis of the external auditory canal andoften deafness.

A child with TCS may have sleep apnea [4], conductive hearing loss, which may require a resource to provide child hearing aids. Some individuals can be affected severally, and they may develop lifethreatening breathing problems known as infantile apnea. When infant with Treacher-Collins Syndrome is scheduled for mandibular surgery under general endotracheal anesthesia, the fiber optic intubation method through a laryngeal musk airway, described by Ellis et al can be successfully used in small infants with Treacher Collins Syndrome $[5,6]$.

Ophthalmic findings associated with TCS include: antimongoloidal palpebral position, narrowed tear ducts (dacrostenosis), notching (coloboma) of the lower eyelid, downward angle of the upper and lower eyelids (downward slanting palpebral fissures, partial or complete absence of the lower eyelashesin the inner corner of the eye,drooping eyelids, vision loss. Dental findings developed among $60 \%$ of individuals with TCS. More often seen are : missing teeth (tooth agenesis), discoloration of the teeth (enamel opacities), widely-spaced teeth., skeletal open bite, bite distal (distalisation of the mandible), "profile of a bird", abnormal eruption of certain teeth (ectopic eruption of maxillary first molars) and malocclusion (improper positioning of the teeth and jaw) andhypoplasia of the mandible jaw with a uniqueconcavity on the lower edge of the mandible, which can be seen well in cephalometric radiograph. Less frequently included findings, associated with TCS are: Congenital heart defect, Abnormal scalp hair pattern (front of the ears and extending toward the cheeks), an abnormally wide mouth (macrostomiaoccur in 15\% of cases), notching of the upper eyelid, hypoplasia or absence of zygomatic bones, widely spaced eyes, nasal deformity, cleft palate and highly arched roof of the

Correspondence to: Vesna Ambarkova PhD,.MSc, DDS, University St. Cyril and Methodius, Faculty of Dental Medicine, Department of Paediatric and Preventive Dentistry, Mother Theresa 17 University Dental Clinic Center Sv. Pantelejmon, Skopje 1000, Republic of Macedonia, Tel: 38970686333; E-mail: vesna.ambarkova@gmail.com

Received: June 03, 2017; Accepted: June 26, 2017; Published: June 29, 2017 
mouth (high Gothic palate accompanied by a cleft palate in $30 \%$ of cases).

The Orthodontic treatment is focuses on the expansion of the upper jaw with mobile devices. If the cleft palate is present, the design of the orthodontic applianceis specially adapted. In thepresence of the permanent dentition application of fixed orthodontic appliance is indicated, in order to establish satisfactory intercuspation and establishproper leveling of the jaws arches. Angle Class II skeletal relationship of the jaws is retained because of the underdevelopment of the lower jaw.

Better performance in school is ensure by treatment of hearing loss. The children with Treacher-Collins syndrome have to be followed by a plastic surgeon because they may need a series of operations to correct birth defects. Receding chin and other changes in face structure can be corrected by plastic surgery [7-9].

Because Treacher Collins syndrome affects multiple body systems, experienced, multidisciplinary team care is extremely important in achieving the best outcomes for physical and psychosocial needs associated with this syndrome, including surgical repair, airway management, feeding and breathing support, orthodontic needs, speech language therapeutic follow-up [10], management of vision and hearing problems and long-term follow-up care.

\section{References}

1. Trainor P, Sanchez-Lara P, Dixon M (2017) The Physicians's Guide to Treacher-Collins
Syndrome. The National Organization for Rare Disorders. Guides for Physicians.

2. De Peratta MSP, Mouguelar VS, Sdrigotti MA, Ishiy FAA, Fanganiello RD, et al. (2016) Cnbp ameliorates Treacher Collins Syndrome craniofacial anomalies through a pathway that involves redox-responsive genes. Cell Death and Disease 7: e2397. [Crossref]

3. Trainor PA, Dixon J, Dixon MJ (2009)Treacher Collins syndrome: etiology, pathogenesis and prevention. European Journal of Human Genetics 17: 275-283. [Crossref]

4. Damlar I, Altan A, Turgav B, Kilic S (2016) Management of obstructive sleep apnea in a Treacher Collins syndrome patient using distraction osteogenesis of the mandible. $J$ Korean Assoc Oral Maxillofac Surg 42: 388-392. [Crossref]

5. Fuentes R, De la Cuadra JC, Lacassie H, González A (2016) Difficult fiberoptic tracheal intubation in 1-month-old infant with Treacher Collins Syndrome. Rev Bras Anestesiol [Crossref]

6. Marques-Pires R, Trindade H2 (2017) The airway approach to a neonate with Treacher Collins syndrome - Case report. Rev Esp Anestesiol Reanim 64: 233-236.[Crossref]

7. Ligh CA, Swanson J, Yu JW, Samra F, Bartlett SP, et al. (2017) A Morphologic Classification Scheme for the Mandibular Hypoplasia in Treacher Collins Syndrome. $J$ Craniofac Surg [Crossref]

8. Sainsbury DC, George A, Forrest CR, Phillips JH (2017) Bilateral Malar Reconstraction Using Patient-Specific Polyether Ketone Implants in Treacher-Collins Syndrome Patients With Absent Zygomas. J Craniofac Surg 28:515-517. [Crossref]

9. Ueda K, Nuri T, Shigemura Y (2016) Malar Reconstraction Using Y-V Advancement Flaps after Tissue Expansion in Treacher Collins Syndrome. Plast Reconstr Surg Glob Open 4: e715 [Crossref]

10. Massi G, FranÇa DR, Santoe RS, Ribas A, Fonseca VD, et al. (2016) Speech language pathology findings in a Treacher Collins syndrome patient. Int Tinnitus J 20: 31-5. [Crossref]

Copyright: (C2017 Vesna A. This is an open-access article distributed under the terms of the Creative Commons Attribution License, which permits unrestricted use, distribution, and reproduction in any medium, provided the original author and source are credited. 